\title{
Injury Profile of a Professional Soccer Team in the Premier League of Iran
}

\author{
Mohammad Hassabi*1,2, MD; Seyed Mohammad-Javad Mortazavi ${ }^{1,3}$, MD; Mohammad-Reza Giti ${ }^{3}$, MD; \\ Majid Hassabi ${ }^{1}$, MD; Mohammad-Ali Mansournia ${ }^{1}$, MD; Sara Shapouran ${ }^{1}$, MD
}

\author{
Authors' Affiliation: \\ 1. Sports Medicine Research \\ Center, Tehran University of \\ Medical Sciences, Tehran, IR \\ Iran \\ 2. Taleghani Hospital, Shahid \\ Beheshti University of Medical \\ Sciences, Tehran, IR Iran \\ 3. Department of Orthopedic \\ Surgery, Tehran University of \\ Medical Sciences, Tehran, IR \\ Iran

\footnotetext{
* Corresponding Author;

Address: Sports Medicine Research Center, No 7, Al-e-Ahmad Highway, P.O. Box 14395-578, Tehran, IR Iran
}

E-mail: hassabi@yahoo.com

Received: Jul 21, 2010

Accepted: Nov 06, 2010

Key Words: Soccer; Football; Athletic Injuries; Contusions; Sports

\begin{abstract}
Purpose: Despite numerous studies which have been done regarding soccer injuries worldwide, there is lack of available data considering the epidemiology of injuries in the Iranian soccer premier league, although it is the most popular sport in the country. The main goal of this research was to determine the incidence of physical injuries in the studied population, considering other characteristics such as site, type and mechanism as well.
\end{abstract}

Methods: Twenty one adult male professional soccer players (age $\mathbf{2 4} \pm \mathbf{3}$ ), members of a team (Tehran-Pas) participating in Iranian premier league, were followed during a 4-month period. The injury characteristics and exposure times were recorded by the team physician during all the matches and training sessions.

Results: The total exposure time was 2610 playing hours (2352 h of training versus $258 \mathrm{~h}$ of competition). Eighty six percent of the injuries were acute. Incidence of acute injuries was 16.5 (95\% CI: 12-22) per 1000 hours of playing (11.5 per $1000 \mathrm{hrs}$ of training and 62 per 1000 hrs of competition). The most common types of injuries were strains followed by contusions, each of which constituted $30 \%$ of acute injuries. More than $80 \%$ of injuries occurred in lower limbs, especially in thigh and groin regions. Nearly $60 \%$ of acute injuries occurred in dominant side of the body, and collision was the reason of about half of the acute injuries. Severity of more than $\mathbf{7 0 \%}$ of the injuries was minor. On average each injury had led the player being off the field for about 10 days.

Conclusion: The incidence of injury in this research is in range of numbers obtained in important international tournaments but the rate of injuries during training sessions is higher than comparable studies.

Asian Journal of Sports Medicine, Vol 1 (No 4), December 2010, Pages: 201-208

\section{INTRODUCTION}

Ooccer is the most popular sport worldwide. More
than 200 million people play soccer around the world $^{[1,2,3]}$. According to estimates of Fédération Internationale de Football Association (FIFA), the average treatment cost is 150 U.S. dollars per injury that leads to about 30 billion dollars a year for 
treatment of injuries in soccer around the world ${ }^{[4]}$. Compilation of prevention programs requires data collection about prevalence of injuries, risk factors related to dangerous aspects and situations of the games $^{[5]}$.

Soccer injury is a generic word. Reviewing the existing literature shows that there are differences on its definition except that the injury should be caused by participating in a soccer activity ${ }^{[6]}$. In recent studies a player is considered injured when he/she cannot attend the next match or next practice session ${ }^{[1,6]}$. Fédération

Internationale de Football Association Medical Assessment and Research Centre following the first world congress on sports injury prevention in Oslo, June 2005, agreed that the term "Medical attention" be used to express the medical condition of the player by a competent doctor and for assessment of "player unable to participate in future training or competition", independent of real training session taking place the next day and selection of players in the team composition for next competition. The Word "future" is applied to any time after the occurrence of his injury, including the day the injury happened. Multiple injuries, which happen in a single event, should be recorded as an injury with multiple diagnoses. Injuries that have no relevance to participation of the player in competitions or training sessions should not be recorded as soccer injuries ${ }^{[7]}$.

According to previous studies muscle strains, contusions and sprains constitute more than $75 \%$ of professional players' injuries ${ }^{[5,9]}$. Players who compete in higher levels suffer from more injuries than players who compete in lower levels ${ }^{[1,2,8,9]}$. Injuries of the lower limbs form 60 to 85 percent of all soccer injuries in both genders, in which thigh, knee and ankle are the most common sites ${ }^{[1,2,3,5,9]}$. Upper body and head injuries are more common among goal keepers ${ }^{[1,10]}$. More than half of the injuries is caused by collision between players ${ }^{[8,11]}$, and most of the others occur during actions such as running, shooting, turning and hitting the ball with head ${ }^{[3,5]}$. In a study on British major league danger of getting injured was higher during the first and the last 15 minutes of the match. Risk of injury was higher in the areas in which competition for owning the ball was tenser (midfield, attack and defense regions) ${ }^{[5]}$.
Pre-season conditioning exercises may minimize severity and overall count of some injuries ${ }^{[12]}$. Muscle fitness and flexibility can affect muscular injuries. Players with low hamstring power or short-headed hamstring or quadriceps muscles are at greater risk of injuries $^{[3,13]}$.

Risk of injury is higher during competitions compared with training sessions $\mathrm{s}^{[1,5,8,11,14,15]}$. Gender and age of players, improvement of technique, the dominant side of player (being right-footed or leftfooted), game score, playing in home or on opponent field, fair play and condition of soccer fields are mentioned as other factors that may have influence on incidence of soccer injuries ${ }^{[1,3,5,10,16]}$.

\section{METHODS AND SUBJECTS}

In this prospective study, physical injuries caused by participation in competition and practice sessions during the second half of Iranian premier soccer league 2005-06 among players of the sample team was recorded. The team physician, who was present during all trainings and competitions, had been requested to keep the records of training time and the number of participants on a daily log and records of injuries and their characteristics in the forms of injury report. Injuries and their type had been diagnosed by the team physician. Para-clinical studies and consultations had been implemented when there was an indication. Studied population consisted of 21 male soccer players with an average age of 24 years (SD: 3). Their injuries had been recorded throughout the second half of the league, started with the first training session and ended with the final match, a hole duration of four months. Injury properties which were paid attentions to were type, severity and site of injury, time and mechanism of happening and if happened during the match or training, the post of player at the time of occurrence and the place in the field where injury happened.

In this study, injury was defined as any physical damage to the player because of participating in any soccer related activity which caused at least losing one training session or a match, or required at least one day 
of rest. Acute injury was considered as a type of injury that followed a distinct event or action such as a contact and a kind of movement with a clear occurrence time. On the other hand, chronic injury referred to damage for which the exact time of occurrence was not clear due to its gradual nature.

Severity of the injury was based on the required rest duration, which was defined by the number of days that the player could not participate in trainings because of injury. Injuries, which did not need more than one week of rest, were considered minor while injuries which required more than one week but a maximum of four weeks of rest were considered moderate, and those which led to more than four weeks of rest were considered severe. In the injury report form, the playing field has been divided into 18 areas (Fig. 1) and the team physician was asked to mark the area of incidence of each injury during the matches.

\section{RESULTS}

In the period of study, 80 training sessions including 2352 person-hour and 16 matches including 258 person-hour were monitored. The overall number of recorded injuries was 50 including 43(83\%) acute injuries and the rest were chronic injuries. Accordingly, the incidence of acute physical injuries was calculated to be 16.5 [95\% confidence interval (95\% CI): 12-22] injuries per 1000 hours of exposure (trainings + competitions) (Table 1).

Twenty seven cases of acute injuries (63\%) happened during trainings and 16 cases $(37 \%)$ occurred during the matches. Therefore, the incidence rate of acute injuries during trainings was 11.5 (95\% CI: 8$16.5)$ per 1000 hours of training and 62 (95\% CI: 38101) per 1000 hours of competition (Table 1). Accordingly, the relative incidence of injury in

Among the occurred injuries during competitions, the most cases $(50 \%)$ belonged to defense positions and after that in a descending manner were midfielders (31.3\%), offensives (12.5\%) and goalkeepers (6.3\%). Fifty eight percent of injuries were in the dominant side, significantly $(P=0.02)$ more than the cases in the non-dominant side of the body (34\%). The other cases included double-sided or centered injuries.

Most of injuries ( $>80 \%$ ) happened on lower limbs, especially on thigh and groin regions (Table 2). Among acute injuries, muscle sprain and soreness, each including $30 \%$ of cases, were the most common types of injuries. More details are shown in Table 3. Totally, two types of chronic injury have been reported, $57 \%$

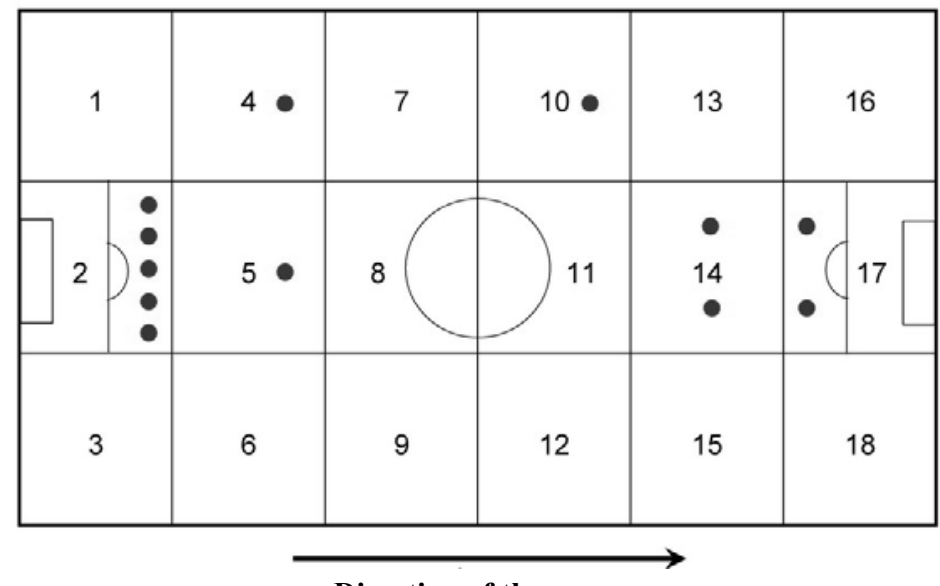

Each circle represents one injury Missing values: •••• (4 cases)

Fig 1: Distribution of injuries by considering the area in the playing field 
Table 1: Incidence rates of acute injuries

$\begin{array}{lcc}\text { During } & \text { Incidence Rate * } & \mathbf{9 5 \%} \text { confidence interval } \\ \text { Total (Training + Competition) } & 16.5 & 12-22 \\ \text { Training } & 11.5 & 8-16.5 \\ \text { Competition } & 62 & 38-101\end{array}$

* Injury/ $1000 \mathrm{hr}$ exposure

were chronic bursitis or tendonitis and $43 \%$ were chronic muscle sprains.

Eighty five percent of acute muscle sprains had involved thigh and groin regions and the rest of them had been in lower legs. Seventy seven percent of contusions had been located below knees. Nearly $80 \%$ of acute injuries needed one week or a shorter period of rest which placed them in mild injury category. Fourteen percent of injuries were moderate in severity and needed more than one, but fewer than or equal to four weeks of rest, while the other $7 \%$ of injuries required more than four weeks of rest which placed them in the severe injury category. About $30 \%$ of chronic injuries had moderate severity and the rest were mild.

Nearly half of acute injuries had happened as a result of collisions with other players. Injuries happened during running or other individual activities and overuse injuries were second and third mechanisms of injuries respectively according to the incidence rate (Table 4). Frequencies of injuries between the two halves were not significantly different. Besides, there was no significant difference between the frequency of injuries at the times of being behind on scores or the times of advantage. Ten cases $(62.5 \%)$ of the duringcompetitions injuries occurred in the home matches

Table 2: Distribution of injuries considering the affected site

\begin{tabular}{|c|c|c|c|c|c|}
\hline & \multicolumn{3}{|c|}{ Acute injuries } & \multicolumn{2}{|c|}{ Chronic injuries } \\
\hline & Site & Quantity & Distribution & Quantity & Distribution \\
\hline \multirow{6}{*}{$\begin{array}{l}\text { LOWER } \\
\text { LIMBS }\end{array}$} & Foot & 6 & $14 \%$ & 0 & $0 \%$ \\
\hline & Ankle & 6 & $14 \%$ & 1 & $14.3 \%$ \\
\hline & Lower leg & 6 & $14 \%$ & 0 & $0 \%$ \\
\hline & Knee & 3 & $7 \%$ & 2 & $28.6 \%$ \\
\hline & Groin \& Thigh & 14 & $32.5 \%$ & 3 & $42.9 \%$ \\
\hline & Sum & 35 & $81.5 \%$ & 6 & $85.8 \%$ \\
\hline \multirow{4}{*}{$\begin{array}{l}\text { UPPER } \\
\text { LIMBS }\end{array}$} & Hand & 1 & $2.3 \%$ & 0 & $0 \%$ \\
\hline & Elbow & 1 & $2.3 \%$ & 0 & $0 \%$ \\
\hline & Shoulder & 1 & $2.3 \%$ & 0 & $0 \%$ \\
\hline & Sum & 3 & $7 \%$ & 0 & $0 \%$ \\
\hline \multirow{3}{*}{$\begin{array}{r}\text { Head and } \\
\text { Face }\end{array}$} & Head & 2 & $4.6 \%$ & 0 & $0 \%$ \\
\hline & Mouth & 1 & $2.3 \%$ & 0 & $0 \%$ \\
\hline & Sum & 3 & $7 \%$ & 0 & $0 \%$ \\
\hline \multirow{3}{*}{ Trunk } & Low back & 2 & $4.6 \%$ & 0 & $0 \%$ \\
\hline & Abdomen & $\mathbf{0}$ & $0 \%$ & 1 & $14.3 \%$ \\
\hline & Sum & 2 & $4.6 \%$ & 1 & $14.3 \%$ \\
\hline Total & & 43 & $100 \%$ & 7 & $100 \%$ \\
\hline
\end{tabular}


Table 3: Distribution of acute injuries by considering type of injury

$\begin{array}{lccc}\text { Type of injury } & \text { Quantity } & \text { Distribution } & \text { Incidence Rate }^{*} \\ \text { Muscle strain } & 13 & 30.2 \% & 5 \\ \text { Contusion } & 13 & 30.2 \% & 5 \\ \text { Sprain/ Ligament injury } & 7 & 16.3 \% & 2.7 \\ \text { Fracture } & 3 & 7 \% & 1.1 \\ \text { Bursitis/ Tendinitis } & 2 & 4.6 \% & 0.8 \\ \text { Muscle spasm } & 2 & 4.6 \% & 0.8 \\ \text { Concussion } & 2 & 4.6 \% & 0.8 \\ \text { Jiont dislocation/ Luxation } & 1 & 2.3 \% & 0.4 \\ \text { Sum } & 43 & 100 \% & 11.5\end{array}$

* Per 1000 hours of exposure (training + competition)

and the others (6 cases) happened in the opponents' homes matches. More than $60 \%$ of during-competitions injuries happened in areas 2, 5, 14 and 17 of the field which are the regions in front of the goals on both sides of the field (Fig. 1).

Date of return for 46 injuries, out of a total of 50 recorded injuries is reported. Absence from practice and matches was 361 and 434 respectively. Hence, on average, 8 days out of trainings and 9.5 days out of competitions for each injury had been wasted.

\section{DISCUSSION}

The overall rate of injuries is consistent with previous studies (17-24 per 1000 hours of exposure $)^{[5]}$, although there are other articles which report higher ${ }^{[5,8,11]}$ or lower ${ }^{[14,15]}$ rates. Lower rates are probably because of including non-professional population, younger athletes or women, whereas higher rates often include studies of tournaments in which proportion of matches to training sessions are higher. Most of previous studies $^{[1,9,11,12,14,15,16]}$ had shown a higher incidence of injuries during competitions rather than training sessions. The incidence rate of injury in this research is in accordance with important international tournaments such as world cup, Olympic and British league (44-81 injuries per 1000 hours of exposure $)^{[5,8,11,17]}$. These values are higher than what have been considered by some other authors for the time of competitions $[1,4,12,14]$, and it may be due to the differences between the nature, importance and intensity of competitions ${ }^{[8]}$.

The incidence rates of injuries during trainings have been reported to be lower in other studies (3-7.5 per

Table 4: Distribution of acute injuries by considering mechanism of injury

$\begin{array}{lcc}\text { Contact } & \mathbf{1 9} & \mathbf{4 4 . 2 \%} \\ \text { Running/ other individual activity }{ }^{*} & 7 & 16.3 \% \\ \text { Overuse } & 4 & 9.3 \% \\ \text { Falling } & \text { (1) } \\ \text { Ball Contact } & 3 & 7 \% \\ \text { Diving (goalkeeper) } & 2 & 4.6 \% \\ \text { Unknown } & 1 & 2.3 \% \\ \text { Sum } & 7 & 16.3 \% \\ \text { * without contact or contact was not the reason } & 43 & 100 \% \\ \text { \# without contact } & & \end{array}$


1000 hours) than what we have found ${ }^{[1,15]}$. The higher level might be associated with improper using of protective equipments during trainings, insufficient pre-season preparation, sudden movements without proper warm-up, insufficient knowledge of team members, type and volume of exercise ${ }^{[15.18]}$.

Frequency of injuries in the dominant side of the body was significantly higher than non-dominant side. It has not been considered in other works on soccer epidemiology and there is no information to compare these data, but a study in Australia has shown more muscle sprains in dominant side of the "football" players $^{[19]}$.

Consistent with other reports ${ }^{[1,9,11,14,16,20]}$, lower limb injuries were significantly more than upper limb injuries in this study. Soft tissue injuries such as muscle strains, contusions and sprain/ligament injuries contain the most portions of acute injuries which confirm other studies ${ }^{[1,4,11,14]}$. Most cases of muscle injuries happened in thigh and groin regions. Dedicating sufficient time for preparation before the training season, screening examinations to discover the players who are not flexible enough and trying to treat their problems, education of players and coaches to understand the importance of warm-up before the beginning of main practice and the necessity of a complete treatment and rehabilitation of injuries before the players return to the field are effective factors that may reduce the incidence of muscle $\operatorname{sprain}^{[1,4,13,18,21]}$. Since most cases of contusions have occurred in the under the knee areas, it seems that greater emphasis on the use of protective equipment, especially during trainings can reduce the intensity and number of such injuries $^{[4]}$. Joint sprains and ligament injuries were the third most frequent injuries. Doing proprioceptive and balance exercises, taping of unstable joints and completing treatment course of earlier injuries may reduce the damage of this kind of injuries ${ }^{[21,22,23]}$.

In this study, consistent with previous studies ${ }^{[5,11]}$, the most frequent mechanism of injury was collision of players. In study of mechanisms of injuries in English premier league, the most frequent contacts which had led to injury were the results of being tackled, tackling, and being charged ${ }^{[5]}$. In order to reduce incidence and severity of contact injuries, more intense enforcement of law by referees ${ }^{[8]}$, and more emphasis on proper usage of protective measures can be effective ${ }^{[4]}$. By better planning of strength and proprioceptive exercises $^{[23]}$ and also improving the performance techniques the incidence of non-contact injuries may be reduced.

Most injuries happened during the time that both teams were at the same score. This might be because of the fact that teams had been at equal score for most of the match times. Anyway, there is no significant difference between the injury frequencies when the team was ahead or when the team was behind on scores. It had seemed before that during outside-home competitions injury rate was higher than inside-home matches, considering more psychological pressure, changes in environmental conditions and unfamiliarity with the playing field. However, the studies on English premier league did not show any meaningful difference ${ }^{[5]}$. Furthermore, in our study the injuries in home matches were even more than outside-home competitions. More research is needed on this subject to obtain a certain conclusion.

As it seems logically correct, most of injuries have happened in front of goals which means in defense and attack regions. These regions can be considered as the places in which most of the challenges for taking the ball happen. Study on injuries in English premier league also shows similar results ${ }^{[5]}$.

Regarding the recovery periods, it can be inferred that each injury keeps the player away from participation for a mean period of about 10 days. This shows the importance of using more efficient methods and skilled medical personnel to avoid injuries and treating the injured athletes.

Some difficulties and limitations of this study can be noted as follows: It is possible that an injured player had not sought medical advice because of fearing of being excluded or assuming that injury is not important. In case of delayed visit to doctor for an acute injury during the match, it is probable that the accuracy of recordings is lower, especially in time of the match, region of the field, occurrence mechanism, and match score at the time of occurrence of injury. Stressful conditions of competitions and also priority of diagnosis and treatment of injuries and the likelihood of multiple simultaneous injuries may affect accuracy of data entry in forms. 


\section{CONCLUSION}

The incidence of injury in this research is in range of numbers obtained in important international tournaments but the rate of injuries during training sessions is higher than comparable studies. Thus, it seems that seeking methods to decrease the number of injuries during training sessions is a priority. The incidence of injuries during training sessions may reduce by improving training techniques, precise usage of protective equipments during trainings and education of players.

\section{ACKNOWLEDGMENTS}

Our thanks to authorities, coaches and other respected staff of Pas football club at the time, especially Mr. Ajorlou and Mr. Mohammad Esmaeili. We respect Sports Medicine Research Center of Tehran University of Medical Sciences for financial support of the project and appreciate the helps of Dr Vahid Ziaee, Dr Ramin Kordi and Dr Farzin Halabchi. Permission for human studies has been acquired from research committee of Tehran University of Medical Sciences under the project number of 4311 .

\section{REFERENCES}

1. Ekstrand J. The risk of injury and injury distribution. In: Ekstrand J, Karlsson J, Hodson A, (eds). Football Medicine. London: Martin Dunitz. 2003; Pp:1-9.

2. Kucera KL, Marshall SW, Kirkendall DT, et al. Injury history as a risk factor for incident injury in youth soccer. Br J Sports Med. 2005;39:462-6.

3. Emery CA, Meeuwisse WH, Hartmann SE. Evaluation of Risk Factors for Injury in Adolescent Soccer (Implementation and Validation of an Injury Surveillance System). Am J Sports Med. 2005;33:1882-91.

4. Giza E, Micheli JL. Soccer Injuries. In: Maffulli N, Caine DJ, (eds). Epidemiology of Pediatric Sports Injuries: Team Sports. Med Sport Sci. Basel: Karger. 2005;49:140-69.

5. Rahnama N, Reilly T, Lees A. Injury Risk Associated with Playing Actions during Competitive soccer. Br J Sports Med. 2002;36:345-59.

6. Junge A, Dvorak J. Influence of Definition and Data Collection on the Incidence of Injuries in Football. Am J Sports Med. 2000;28:S40-6.

7. Fuller CW, Ekstrand J, Junge A, et al. Consensus statement on injury definitions and data collection procedures in studies of football (soccer) injuries. Br J Sports Med. 2006;40:193-201.

8. Dvorak J, Junge A, Grimm K, Kirkendall D. Medical report from the 2006 FIFA World Cup Germany. Br J Sports Med. 2007; 41:578-81.

9. Wong P, Hong Y. Soccer injury in the lower extremities. Br J Sports Med. 2005;39:473-82.

10. Fuller CW, Junge A, Dvorak J. A six year prospective study of the incidence and causes of head and neck injuries in international football. Br Sports Med. 2005;39:3-9.

11. Junge A, Langevoort G, Pipe A, et al. Injuries in Team Sport Tournaments During the 2004 Olympic Games. Am J Sports Med. 2006;34:565-76.

12. Heidt RS, Sweeterman LM, Carlonas RL, et al. Avoidance of Soccer Injuries with Preseason Conditioning. Am J Sports Med. 2000;28:659-62.

13. Witvrouw E, Danneels L, Asselman P, et al. Muscle Flexibility as a Risk Factor for Developing Muscle Injuries in Male Professional Soccer Players. Am J Sports Med. 2003;31:41-6. 
14. Le Gall F, Carling C, Reilly T, et al. Incidence of Injuries in Elite French Youth Soccer Players A 10-Season Study. Am J Sports Med. 2006;34:928-38.

15. Morgan BE, Oberlander MA. An examination of injuries in major league soccer. The inaugural season. Am J Sports Med. 2001;29:426-30.

16. Faude O, Junge A, Kindermann W, Dvorak J. Injuries in Female Soccer Players A Prospective Study in the German National League. Am J Sports Med. 2005; 33:1694-700.

17. Junge A, Dvorak J, Graf-Baumann T. Football injuries during the World Cup 2002. Am J Sports Med .2004;32:23-7S.

18. Arnason A, Sigurdsson SB, Gudmundsson A, et al. Risk Factors for Injuries in Football. Am J Sports Med. 2004;32:5S-16S.

19. Orchard JW. Intrinsic and Extrinsic Risk Factors for Muscle Strain in Australian football. Am J Sports Med. 2007;29:300-3.

20. Peterson L, Junge A, Chomiak J, et al. Incidence of Football Injuries and Complaints in Different Age Groups and Skill-Level Groups. Am J Sports Med. 2000;28:51-7.

21. Junge A, Rösch D, Peterson L, et al. Prevention of Soccer Injuries: A Prospective Intervention Study in Youth Amateur Players. Am J Sports Med. 2002;30:652-9.

22. Mohammadi F. Comparison of 3 Preventive Methods to Reduce the Recurrence of Ankle Inversion Sprains in Male Soccer Players. Am J Sports Med. 2007;35:922-6.

23. Olsen L, Scanlan A, MacKay M, et al. Strategies for prevention of soccer related injuries: a systematic review. Br J Sports Med. 2004;38:89-94. 